\title{
Carbon metabolism of soil microbial communities of restored forests in Southern China
}

\author{
Yun Wang • Zhiyun Ouyang $\cdot$ Hua Zheng • \\ Xiaoke Wang $\cdot$ Falin Chen $\cdot$ Jing Zeng
}

Received: 24 November 2010 / Accepted: 3 March 2011 /Published online: 19 April 2011

(C) Springer-Verlag 2011

\begin{abstract}
Purpose The structure and dynamics of carbon metabolic process of the soil microbial community in restored forests were dependent on the methods employed in reforestation and subsequent management. To find an appropriate method to restore degraded forests and to assess the ecological benefits of restorations, we studied community level physiological profiles of soil microbial communities in forests in Southern China that were restored by three different methods.

Materials and methods Community level physiological profiles of soil microbial communities in restored introduced slash pine (Pinus elliottii) plantation, restored native Masson pine (Pinus massoniana) plantation, and natural secondary forest in Southern China were studied based on outcomes of the Biolog ${ }^{\text {TM }}$ Ecoplates incubation. For each type of restored forest, 15 experimental plots were randomly selected in Southern China. In each plot, three composite samples of 0 to $10 \mathrm{~cm}$ depth were obtained from three subplots for the analyses.

Results and discussion It was found that the soil microbial communities of three types of restored forests were capable of metabolizing all 31 preselected carbon substrates on Biolog ${ }^{\mathrm{TM}}$ Ecoplates. However, the soil microbial community of the natural secondary forest was more diverse in structure of carbon metabolism, and more efficient in
\end{abstract}

Responsible editor: Chengrong Chen

Y. Wang $\cdot$ Z. Ouyang $(\bowtie) \cdot H$. Zheng $\cdot X$. Wang $\cdot$ F. Chen

J. Zeng

State Key Laboratory of Urban and Regional Ecology,

Research Center for Eco-Environmental Sciences,

Chinese Academy of Sciences,

Beijing 100085, People's Republic of China

e-mail: zyouyang@rcees.ac.cn utilizing the carbon substrates than those of the Masson pine and slash pine plantations that had to acclimate and adopt different biochemical pathways to metabolize some of the carbon substrates. Soil available N content, moisture content, organic $\mathrm{C}$ content, microbial biomass $\mathrm{C}$ content, $\mathrm{pH}$, clay content, and Shannon-Wiener diversity index of tree layer were factors contributing to the carbon source utilization structure of the soil microbial communities for the three types of restored forests.

Conclusions The soil microbial communities of all three types of restored forests would provide the same ecological services in metabolizing carbon sources in the forest soils. The microbial community of the natural secondary forest was consistently more efficient in carbon utilization than those of the Masson pine and slash pine plantation and often the Masson pine plantations were more efficient than that of the slash pine plantations. The natural secondary forest had a more diverse and stable soil microbial ecosystem and would be more adaptable to and respond more rapidly to environmental changes.

Keywords Carbon source utilization - Ecosystem services . Forest restoration type $\cdot$ Redundancy analysis $\cdot$ Soil microbial community

\section{Introduction}

Restoring degraded terrestrial ecosystems is imperative for healthiness of the environment (Chazdon 2008; Ren et al. 2007) and crucial to sustainable developments (Simmons et al. 2007). The principles and practices of ecosystem restorations have attracted the attention of researchers and policy makers alike (Fu 2010; Roberts et al. 2009). In this respect, the ecological integrity of the forests is vital (Zhao 
et al. 2004; Costanza 1997; Ouyang et al. 1999). It takes a long time for restored forests to reach maturity and realize the ecological benefits (Chazdon 2008). The structure, function, and subsequently services provided by the restored ecosystems often are not clear-cut and may differ with the methods employed to restore the degraded sites, especially the tree species introduced (Chazdon 2008; Ren et al. 2006). Knowledge on the evolution of the ecological environment of restored forests over time (Wardle et al. 2004b; Zhang and Dong 2010) and how the methods of reforestation affect the outcomes (Ren et al. 2006) are important.

Soil microorganisms are the foundation of terrestrial ecosystems and are vital in biochemical cycling of plant nutrients (Fuhrman 2009; Harris 2009) and decomposing plant litters (Whitham et al. 2008; Manzoni et al. 2008). As a result, the structural and process dynamics of soil microbes would regulate the availability of plant nutrients and thus the productivity of primary producers above ground (Harris 2009; Wardle et al. 2004a) and are key factors of soil formation (Harris 2009). Different methods employed in restoration would create different ecoenvironmental settings that directly or indirectly influence the chemical and physical characteristics of the soils (Baudoin et al. 2003; Fierer and Jackson 2006; Zheng et al. 2005) and in turn the organization and structure of soil microbial community (Young and Crawford 2004). When the forest ecosystems are restored, the soils are again conducive for water, nutrients, pollutants, and energy flows (Zheng et al. 2005), the metabolic processes of soil microbes are greatly enhanced (Zheng et al. 2005), and the ecosystem services become fully functional (Benayas et al. 2009; Chazdon 2008).

In natural successions, the native species were allowed to continue after the timber harvesting and the understory, litter layer, and soil microbial community were essentially intact awaiting the secondary forest to emerge. The ecosystem services of forests in this case are fully maintained at the least costs (Chazdon 2008). On deforested and degraded landscapes, plantations are often established to cultivate native or introduced species for future timber harvests (Chazdon 2008; Ren et al. 2007; Tian et al. 2004). In this situation, the structure and organization of original forest ecosystems are decimated and soil microbial communities must be re-established under the new environment. The plantations are regularly cultivated and the understory is kept to the minimal. As a result, the plantation forests are mono cultured and susceptible to water and nutrients losses (Zheng et al. 2008) both affecting microbial activities of soils. With changed carbon substrates, nutrients, and water supply the soil microbial communities evolved in plantation forests are expected to differ from those of natural secondary forest (Chazdon 2008; Ren et al. 2006; Zheng et al. 2005). Do the functions of soil microbial community be fully restored in plantation forests? We hypothesized that the structure and the dynamics of metabolic processes of soil microbial community in restored forests are dependent upon the methods employed in reforestation and subsequent management.

China has a significant inventory of degraded ecosystems and restorations are imperative to prevent continuing environmental degradation and natural disasters (Liu et al. 2000; Ren et al. 2007). Rehabilitating the degraded forest ecosystems would have far reaching implications in restoring the ecological balances in China's natural environment (Liu et al. 2000). The government has made great effort in forest restoration (Liu et al. 2008). There are 0.53 billion hectares of plantation forests in China, the largest in the world (Ren et al. 2007).

In central and Southern China, only $28 \%$ of the forest is in natural state and the Masson pine (Pinus massoniana) and slash pine (Pinus elliottii) plantations account for 59\% of the forested areas (Ren et al. 2007). This study investigated the carbon metabolisms of soils in forests restored under three different methods in the red soil region of Southern China, namely the natural secondary forest, Masson pine plantation, and slash pine plantation. The aims were to answer two questions. First, do soil microbial communities of a naturally regenerated secondary forest, Masson pine plantation, and slash pine plantation in Southern China have the same functional diversity in terms of utilizing carbon substrates for energy metabolisms? What potential effects do the introduced slash pine species may have on structure, function, and metabolic processes of the soil microbial community? Second, what environmental factors cause the functional diversity in soil microbial communities of the restored forests? The answers would provide information to guide forest restoration in the red soil region in Southern China and may have implications for other regions with similar environmental conditions.

\section{Materials and methods}

\subsection{Study area}

The study area was located in Southern China. It is in the subtropical monsoon moist climate zone where average annual temperature varies from $15^{\circ} \mathrm{C}$ to $25^{\circ} \mathrm{C}$ and annual precipitation varies from 900 to $2,100 \mathrm{~mm}$ (Zhang and Cha 2009). Three types of restored forests, natural secondary forest, slash pine plantation, and Masson pine plantation were included and were denoted as NF, SP, and MP, respectively hereafter. The naturally regenerated secondary forest has received no cultivation and has been disturbed little since re-establishments. The Masson pine is an 
indigenous species of Southern China. Masson pine and slash pine plantations were cultivated every 3 to 4 years, including loosening of surface soils and cutting down of understory vegetation. The investigation and sampling commenced 2 to 3 years following the last time the artificially reforested areas were tended.

\subsection{Site distribution and sampling}

The duration of time since the restoration process is an important factor (Zhang and Dong 2010). It takes P. massoniana and $P$. elliottii plantations 20 years to attain a stable condition and reach maturity (Tian et al. 2004). Thus, all of the plots in this study had been restored from 15 to 25 years ago. For each type of forest restoration, we randomly selected 15 plots on independent stands between the coordinates of 24.89 to $27.32^{\circ} \mathrm{N}, 110.15$ to $112.32^{\circ} \mathrm{E}$ across Southern China. The elevation varies from 90 to $350 \mathrm{~m}$ above sea level (Table 1). All together, 45 plots equally distributed among three types of forest restoration were studied. In each plot, three $10 \times 10 \mathrm{~m}$ soil sampling quadrates were randomly chosen. Within a sampling quadrate, five 0 to $10 \mathrm{~cm}$ depth soil cores were extracted using a $3.6-\mathrm{cm}$ diameter auger and were composite into one sample as the surface soils experienced the most changes during the reforestation process (Meyer et al. 2008). The soil core was extracted at a distance of $50 \mathrm{~cm}$ from trunk of the dominant tree in the quadrate as microbial community might vary with distance to trunk (Saetre and Bååth 2008). A total of 135 samples were collected and were analyzed separately. At the same time, we surveyed the plant community composition above ground, and sampled roots with the same method for soil.

Carbon metabolisms of the soil microbial communities were characterized by the community level physiological profiles (CLPPs) using Biolog ${ }^{\mathrm{TM}}$ EcoPlate (Winding 1994). In summary, $10 \mathrm{~g}$ of fresh soil was suspended in $95 \mathrm{ml}$ of sterile $0.85 \% \mathrm{NaCl}$ solution and agitated for $30 \mathrm{~min}$, and then serially diluted by $10^{-2}$. Each well of a Biolog ${ }^{\mathrm{TM}}$ EcoPlate was inoculated with $150 \mu \mathrm{l}$ of the diluted soil suspension and incubated at a constant temperature of $25^{\circ} \mathrm{C}$. The plates were scanned at wavelength of $590 \mathrm{~nm}$ with a Biolog reader at 12$\mathrm{h}$ intervals for $240 \mathrm{~h}$. One soil sample used one plate that has 31 carbon substrates arranged in triplicates.

Soil microbial biomass $\mathrm{C}$ content was determined with chloroform fumigation method using a $\mathrm{Kc}=0.45$ with fresh soil (Vance et al. 1987). The remaining sample was air dried and used for characterizing physical and chemical properties of the soils (Bao 2000). The sizes of soil particles were measured using a Mastersizer 2000 (Malvern Instruments, Malvern, England) according to Wang et al. (2008) and the particle size distribution were categorized according to the US soil classification system (Huang 1999). Basic physical and chemical characteristics of the soils were summarized (Table 2). Root was scanned with EPSON scanner (EPSON Expression $836 \times \mathrm{L}$ scanning system) and analyzed with WinRhizo software (V5.0, Regent Instruments, Quebec, Canada).

\subsection{Data processing}

Average well color development (AWCD) were calculated according to Garland and Mills (1991) that:

$\mathrm{AWCD}=\sum_{i=1}^{31}\left(C_{i}-r\right) / n$

where $C_{i}$ was the absorption of the $i$ th substrate following the incubation measured in terms of the optical density at wavelength of $590 \mathrm{~nm}\left(\mathrm{OD}_{590}\right), r$ was the comparable absorption of contrast well, $n$ was the number of substrates involved. Negative $C-r$ values were set to be zero (Kohler et al. 2005). For individual substrate, the AWCD versus incubation time, $t$, was fitted to a logistic growth equation (Lindstorm et al. 1998; Mondini and Insam 2003):

$\mathrm{AWCD}_{t}=\frac{K}{1+\exp (-R(t-s))}$

where $K$ was the asymptote of AWCD denoting the carrying capacity of the substrate, $R$ was the exponential growth rate represented by changes of absorbance with respect to change of time, $t$ was the time, and $s$ was the time for AWCD to reach $K / 2$.

The intensity of carbon substrate metabolism, $S$, may be estimated by the area underneath AWCD vs. $t$, and was obtained by integrating Eq. 2 against time $t$ (Hackett and Griffiths 1997) that:

$S=\sum\left(\left(v_{i}+v_{i-1}\right) / 2 \times\left(t_{i}-t_{i-1}\right)\right)$

where $v_{i}$ was the AWCD at time $t=i$. $\sum$ denotes summation for the entire incubation period, if AWCD was scanned every $12 \mathrm{~h}, i$ is from 0 to 20 .
Table 1 Basic characteristics of the restored slash pine plantation (SP), Masson pine plantation (MP), and natural secondary forest (NF) in Southern China

\begin{tabular}{lcrrl}
\hline Reforestation type & $\begin{array}{l}\text { Vegetation } \\
\text { coverage (\%) }\end{array}$ & Elevation (m) & Slope $\left(^{\circ}\right)$ & Dominant species \\
\hline Slash pine plantation & $70-85$ & $92-117$ & $8-29$ & P. elliottii \\
Masson pine plantation & $68-75$ & $107-141$ & $9-15$ & P. massoniana \\
Natural secondary forest & $85-95$ & $90-123$ & $29-31$ & Fagaceae, Theaceae, Lauraceae \\
\hline
\end{tabular}


Table 2 Main characteristics of soils in restored slash pine plantation (SP), Masson pine plantation (MP), and natural secondary forest (NF)

\begin{tabular}{llllllll}
\hline $\begin{array}{l}\text { Reforest } \\
\text { type }\end{array}$ & $\begin{array}{l}\text { Moisture } \\
\text { content }(\%)\end{array}$ & $\begin{array}{l}\text { Bulk density } \\
\left(\mathrm{g} \mathrm{cm}^{-3}\right)\end{array}$ & $\begin{array}{l}\text { Clay } \\
\text { content }(\%)\end{array}$ & $\begin{array}{l}\text { Organic matter } \\
\text { content }\left(\mathrm{g} \mathrm{kg}^{-1}\right)\end{array}$ & $\begin{array}{l}\text { Available N } \\
\text { content }\left(\mathrm{mg} \mathrm{kg}^{-1}\right)\end{array}$ & $\mathrm{pH}$ & $\begin{array}{l}\text { Microbial biomass } \\
\text { carbon content }\left(\mu \mathrm{g} \mathrm{g}^{-1}\right)\end{array}$ \\
\hline $\mathrm{SP}$ & $17.3 \pm 1.5 \mathrm{~b}$ & $1.12 \pm 0.03 \mathrm{a}$ & $15.1 \pm 1.4 \mathrm{a}$ & $30.0 \pm 1.9 \mathrm{~b}$ & $83.3 \pm 8.8 \mathrm{~b}$ & $4.39 \pm 0.01 \mathrm{a}$ & $187 \pm 27 \mathrm{~b}$ \\
$\mathrm{MP}$ & $17.7 \pm 1.3 \mathrm{~b}$ & $1.17 \pm 0.05 \mathrm{a}$ & $9.8 \pm 0.6 \mathrm{~b}$ & $29.4 \pm 2.1 \mathrm{~b}$ & $83.5 \pm 6.6 \mathrm{~b}$ & $4.34 \pm 0.07 \mathrm{a}$ & $174 \pm 35 \mathrm{~b}$ \\
$\mathrm{NF}$ & $24.6 \pm 1.3 \mathrm{a}$ & $0.91 \pm 0.04 \mathrm{~b}$ & $11.4 \pm 0.5 \mathrm{ab}$ & $48.9 \pm 3.7 \mathrm{a}$ & $203.3 \pm 22.8 \mathrm{a}$ & $4.35 \pm 0.07 \mathrm{a}$ & $412 \pm 95 \mathrm{a}$ \\
\hline
\end{tabular}

Values indicate mean \pm standard error of 15 plots and different letters following values of a column denote significant difference between the forest restoration types at $p<0.05$

As $96 \mathrm{~h}$ was nearest to the time $(102 \pm 2 \mathrm{~h})$ to reach one half of maximum AWCD, values at $96 \mathrm{~h}$ were used to assess the ability of soil microbial community to utilize diverse carbon sources included in the Biolog ${ }^{\mathrm{TM}}$ testing protocol via the Shannon-Wiener diversity index and the redundancy analysis (RDA). The richness of carbon source utilization according to the AWCD at $96 \mathrm{~h}$ was the number of wells whose $C-r>0.25$ (Kaufmann et al. 2004) and Shannon-Wiener diversity index, $H^{\prime}$, was calculated as follows (Shannon 1948):

$H^{\prime}=-\sum p_{i} \times \ln p_{i}$

$p_{i}=n_{i} / N$

where $n_{i}$ was the AWCD of the $i$ th substrate and $N$ was the sum of AWCD of substrates all at $t=96 \mathrm{~h}$. For community diversity, $p_{i}$ denoted the relative abundance of the $i$ th species.

\subsection{Data statistics and analysis}

To minimize the experimental errors, triplicates of Biolog ${ }^{\mathrm{TM}}$ EcoPlate carbon sources were inoculated and the outcomes were averaged to obtain the AWCD readings for each quadrate. The AWCD readings of quadrates were then averaged to represent that of a plot. One way randomized analysis of variance (ANOVA) was used to test effects of restoration type on the maximum of AWCD, $K$, carbon source utilization intensity, $S$, richness of carbon source utilization, and $H^{\prime}$, Shannon-Wiener diversity index. If the differences due to restoration type were significant, Turkey's Honestly Significant Difference test was use to separate the significantly different components. The SPSS 16.0 (SPSS INC., Chicago, IL, USA) software package was employed to conduct the ANOVA. The macro in Sigmaplot was used to fit the curve of carbon source and for calculation of the parameters mentioned in Eq. 2.

The redundancy analysis was used to detect interrelationship of carbon source utilization and causative factors based on outcomes of partition the variances, through CANOCO 4.5. "Species" data were centered and "environ- ment" data were standardized (Kaufmann et al. 2004). "Species" was represented by carbon source utilization, i.e., the optical intensity of carbon source calculated by $C_{i}-r$. Thirteen factors were used as causative factors, including soil $\mathrm{pH}$, soil total $\mathrm{C}$ content, soil total $\mathrm{N}$ content, soil total $\mathrm{P}$ content, soil organic matter content, soil available $\mathrm{N}$ content, soil available $\mathrm{P}$ content, soil available $\mathrm{K}$ content, $\mathrm{C} / \mathrm{N}$ in soil, soil moisture content, soil bulk density, soil clay content, soil silt content, soil microbial biomass $\mathrm{C}$ content, litter amount, root surface area, root weight, and Shannon-Wiener diversity index in tree layer, shrub layer, and herb layer. Monte Carlo permutation test (999 permutations) was used to preselect factors that significantly influence carbon source utilization patterns.

\section{Results}

3.1 Effects of forest restoration type on soil microbial biomass $\mathrm{C}$ content

In the restored forests, the soil microbial biomass $\mathrm{C}$ content expressed in mean \pm standard error hereafter varied from $174 \pm 35 \mu \mathrm{g} / \mathrm{g}$ of soil in Masson pine plantation to $412 \pm 95 \mu \mathrm{g} / \mathrm{g}$ of soil in natural secondary forest. The methods employed in the forest restoration significantly influenced microbial biomass $\mathrm{C}$ contents of the soils at $p<0.05$ (see Table 2). The soil microbial biomass $C$ content of the natural secondary forest was significantly higher than those of slash pine plantation and Masson pine plantation $(p<0.05)$. The soil microbial biomass $\mathrm{C}$ content of Masson pine plantation and slash pine plantation however were not significantly different $(p>0.05)$. The soil biomass $\mathrm{C}$ contents of forests restored by three different methods however did not provide information on the structure, function, and diversity of the respective soil microbial communities.

3.2 AWCD and carbon source utility intensity of restored forests

The average well color development described the overall carbon substrate utilizations by the soil microbial commu- 
nities of the restored forests over incubation time (Fig. 1). Forests restored with different methods showed the same development pattern (see Fig. 1). The AWCD generally exhibited a 24 to $48 \mathrm{~h}$ of lag time before metabolic reactions took off. Forty-eight hours after inoculation, the soil microbial community of natural secondary forest produced significantly higher AWCD therefore greater substrate utilization than those in the Masson pine plantation and slash pine plantation $(p<0.05)$. From 60 to $216 \mathrm{~h}$ after inoculation, natural secondary forest consistently produced significantly higher AWCD than that in the slash pine plantation $(p<0.05)$. Neither the AWCD of natural secondary forest and that of Masson pine plantation, nor the AWCD of Masson pine plantation and that of slash pine plantation were significantly different $(p>0.05)$. The exponential growth rates, $R$, of soil microbial communities for forests restored under three methods were not significantly different at $p<0.05$. From 216 until $240 \mathrm{~h}$ of incubation, the AWCD of natural secondary forest and Masson pine plantation were significantly higher than that of the slash pine plantation $(p<0.05)$.

We analyzed $K$, the maximum AWCD and $S$, the incubation time required for microbial growth to reach $K / 2$ of the soil microbial communities of forests restored under three different methods (Fig. 2a). The maximum AWCD of natural secondary forest, Masson pine plantation, and slash pine plantation were $1.64 \pm 0.08,1.49 \pm 0.05$, and $1.33 \pm 0.05$ absorbance units, respectively, in which the maximum AWCD of natural secondary forest was significantly higher than that of the slash pine plantation at $p<0.05$. The maximum AWCD were significantly different pointed to the fact that the soil microbial community of natural secondary forest was invariably more diverse and always exerted the highest ability to metabolize carbon substrates. The time to reach one half of the maximum AWCD, $S$, of

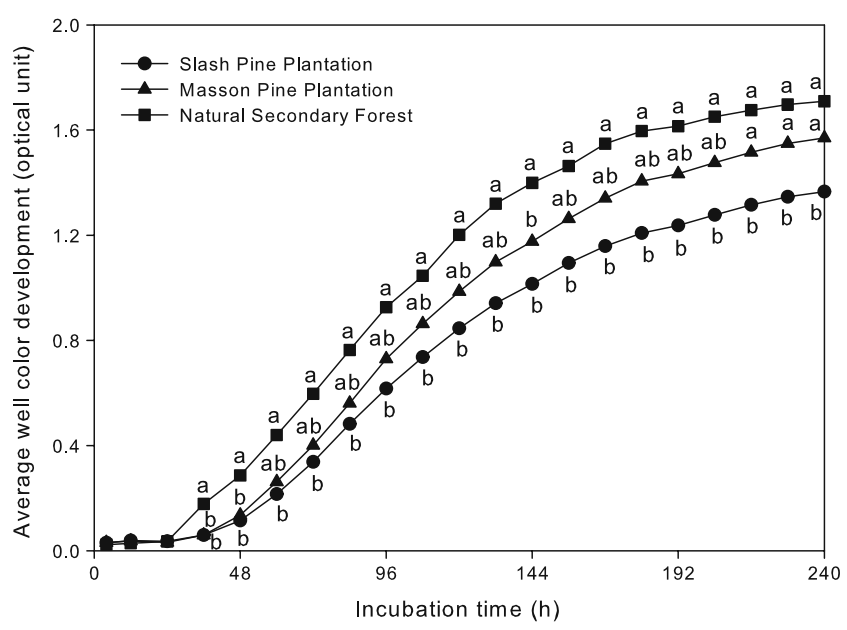

Fig. 1 Average well color development of soils in restored forests. Different letters on the data points denote significant difference at $p<0.05$ forests restored by the three methods was not significantly different to one another. It took an average of $102 \pm 2 \mathrm{~h}$ to reach one half of the maximum AWCD.

The carbon substrate metabolism intensity was the integration of AWCD over incubation time from $t=0$ to $240 \mathrm{~h}$ (see Fig. 2b). It indicated relatively the total carbon utilized by the soil microbial communities and the resulting microbial biomass. Methods used for forest restoration significantly influenced carbon substrate utilization intensity. The soil microbial community of natural secondary forest exhibited greater carbon substrate utilization intensity. It implies that the soil microbial community established under natural secondary forest was capable of consuming carbon substrates at significantly greater efficiency than under the settings of slash pine plantation $(p<0.05)$. Yet, the carbon substrate metabolism intensities of the soil microbial communities under the natural secondary forest and that of Masson pine plantation and those under Masson pine plantation and slash pine plantation were not significantly different $(p>0.05)$.

\subsection{Metabolism diversity}

Carbon source utilization richness depicted the number of substrates a soil microbial community was able to utilize and reflected the diversity of microbial metabolisms. This metrics was significantly affected by the methods that were used to restore forests (Fig. 3a). The mean carbon source utilization richness of natural secondary forest, $25.3 \pm 1.3$, was significantly higher than that of Masson pine plantation, $20.7 \pm 0.8$, and that of slash pine plantation, $19.0 \pm 1.0$ at $p<0.05$. The difference between carbon source utilization richness slash pine plantation and Masson pine plantation was not significant $(p>0.05)$.

Shannon-Wiener diversity index of carbon source utilization varied from $2.92 \pm 0.03$ to $3.15 \pm 0.04$ (see Fig. 3b) and again forest restoration methods significantly influenced the metrics. Shannon-Wiener diversity index of natural secondary forest was significantly higher than those of Masson pine plantation and slash pine plantation $(p<0.05)$. The Shannon-Wiener diversity index of Masson pine plantation and those of slash pine plantation was not significantly different $(p>0.05)$.

The metabolism of each carbon substrate of Biolog ${ }^{\mathrm{TM}}$ Ecoplates was individually evaluated. This would be a more accurate depiction of carbon source utilization. During the 240-h incubation period, the soil microbial communities of restored forests were capable of utilizing all 31 preselected carbon sources. However, the extents of utilization were not the same for each community and not for all of the carbon substrates. The soil microbial community of natural secondary forest was capable of fully utilizing (reached maximum AWCD before $t=240 \mathrm{~h}$ ) 21 
Fig. 2 Mean and standard error of maximum of AWCD and carbon source utility intensity of soil microbial communities of restored slash pine plantation $(S P)$, Masson pine plantation $(M P)$, and natural secondary forest $(N F)$. Different letters on the bars denote significant difference according to methods of forest restoration at $p<0.05$
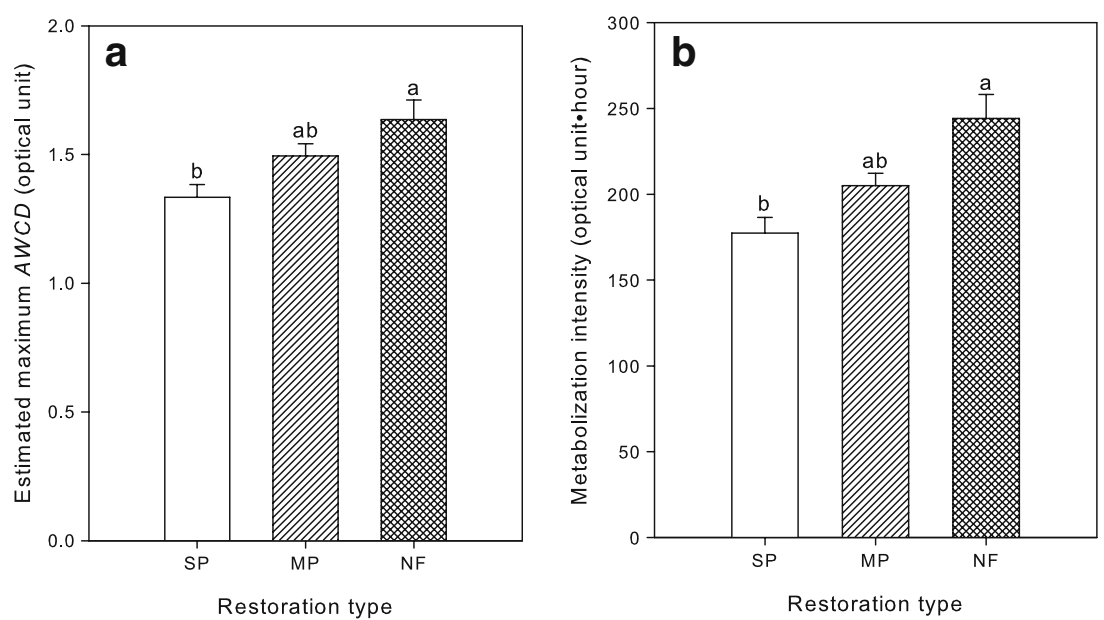

carbon sources, while Masson pine plantation was capable of utilizing 16 of the same 21 carbon sources, and slash pine plantation was capable of utilizing 14 of the same 21 substrate sources. The number of carbon substrates completely utilized by natural secondary forest was significantly higher than that of slash pine plantation at $p<0.05$. Among the 21 carbon sources, the soil microbial community of Masson pine plantation was not able to fully utilize included D-galactonic acid- $\gamma$-lactone, D-xylose, and tween 80 and that of slash pine plantation was not able to fully utilize included $\beta$-methyl-D-glucoside, D-xylose, phenylethylamine, pyruvic acid methyl ester, and tween 40. As the logarithmic growth rates of the soil microbial communities were not significantly different between methods of forest restoration, they were not fully utilized because of a considerably longer lag time that exceeded the average of 24 to $48 \mathrm{~h}$. This indicates that microorganisms capable of metabolizing these substrates were not present in soils of Masson pine and slash pine plantations and the communities had to acclimate in order to metabolize these carbon substrates thus the longer lag times.
There were 12 substrates that were completely utilized by the microbial communities of all three types of restored forests. Among them, the metabolisms of 4-hydroxy benzoic acid, D, L- $\alpha$-glycerol phosphate, D-galacturonic acid, D-glucosaminic acid, L-arginine, L-asparagine, $\mathrm{N}$ acetyl-D-glucosamine, and putrescine were essentially identical in maximum AWCDs in the soils of all three types of restored forests. While for the other part of carbon sources (2-hydroxy benzoic acid, D-mannitol, D-malic acid, and Lphenylalanine), slash pine plantation had significantly lower maximum AWCD than either Masson pine plantation or natural secondary forest $(p<0.05)$. However, the parameter $S$ which characterizes the lag time in natural secondary forest was either shorter than (five in 12 carbon sources) or similar to (seven in 12 carbon sources) those in pine plantations indicating the soil microbial community of the natural forest requires less time for acclimation. Apparently, the biochemical pathways of metabolizing these carbon substrates were not the same in the soil microbial community of natural secondary forest vs. the pine plantations, especially slash pine plantation.
Fig. 3 Mean and standard error of carbon source utilization richness and diversity index of the soil microbial communities of restored slash pine plantation $(S P)$, Masson pine plantation $(M P)$, and natural secondary forest $(N F)$. Different letters on the bars denote significant difference according to methods of forest restoration at $p<0.05$
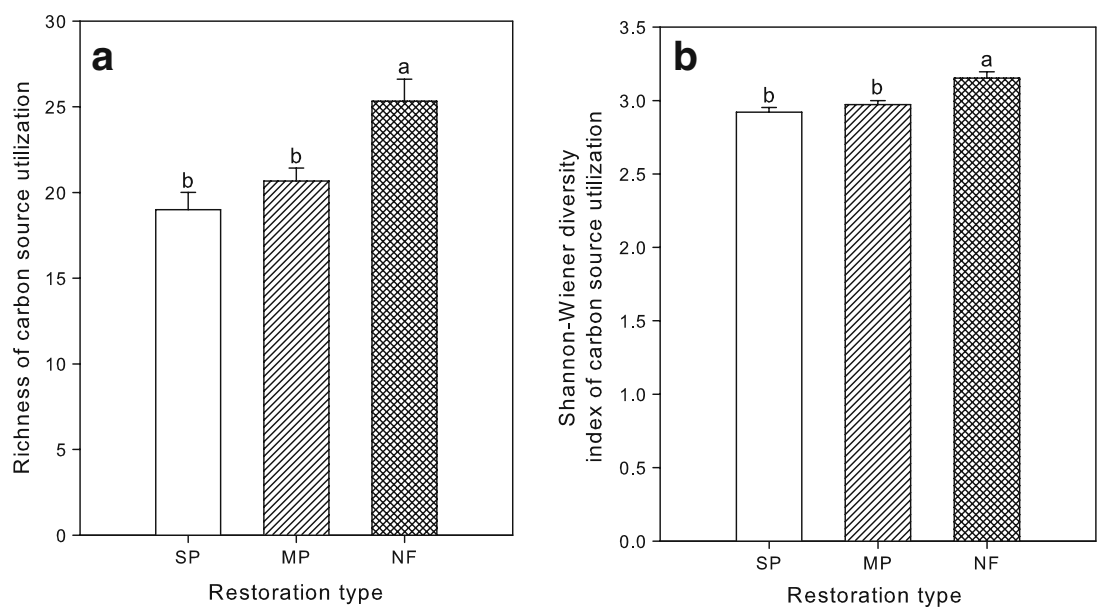
None of the soil microbial community was able to completely metabolize 12 substrates namely i-erythritol, L-serine, $\alpha$-cyclodextrin, 2-hydroxy butyric acid, thereonine, glycogen, itaconic acid, glycyl-L-glutamic acid, D-cellobiose, glucose-1-phosphate, $\alpha$-ketobutyric acid, and $\alpha$-D-lactose. For this group of carbon substrates, the lag time, as characterized by $S$, was considerably longer than those in the category of completely metabolized. Apparently, all three microbial communities had to acclimate in order to metabolize them. The logarithmic metabolic rates were different. For three in 12 carbon sources, the metabolic rates of soil microbial community in natural forest were consistently higher than those of the pine plantations, and for the remaining nine in 12 carbon sources there were no significant difference among forest restoration types. Different biochemical pathways were developed, metabolizing these carbon substrates in the three restored forests.

Judging from the results of $240 \mathrm{~h}$ incubation, all three restored forests have the ability to metabolize the 31 preselected carbon substrates of the Biolog ${ }^{\mathrm{TM}}$ Ecoplate. The carbon sources most frequently utilized completely were carbohydrates, carboxylic acids, and amino acids. The carbon sources most frequently utilized in slash pine plantation and Masson pine plantation were all included in natural secondary forest. Compared with completed utilized carbon sources, most of the partially utilized carbon sources were more complex carboxylic acids and amino acids. Therefore, all three soil microbial communities would provide the same ecological functions in metabolizing carbon sources in the forest soils. The microbial communities of the natural secondary forest was consistently more efficient in carbon utilizations as characterized in terms of the maximum AWCD, logarithmic metabolism rate, and lag time than those of the Masson and slash pine plantation and oftentimes those of the Masson pine plantation were more efficient than those of the slash pine plantation.
3.4 Factor analysis of carbon source utilization structure

The differences in soil microbial communities of these three types of restored forests were results of environmental influences. Environmental factors driving the soil microbial carbon source utilization and their respective contributions to the total variance were sorted out by the redundancy analysis, RDA (Fig. 4). It showed that the first and second axis accounted for $47.7 \%$ and $10.4 \%$ of the variance, respectively $(p<0.01)$ and the accumulated variation of the relationship between carbon source utilization and environmental factors were $75.9 \%$ and $92.4 \%$, respectively. Monte Carlo permutation test was used to identify factors that significantly influenced carbon source utilization. Among them, soil available $\mathrm{N}$ content was the biggest contributor which explained $23.4 \%$ of carbon source utilization variation, followed by soil microbial biomass $\mathrm{C}$ content, soil moisture content, soil clay content, $\mathrm{pH}$, ShannonWiener diversity index of the tree layer, and soil organic matter content which explained $10.4 \%, 7.5 \%, 6.9 \%, 6.2 \%$, $4.8 \%$, and $3.7 \%$, respectively. In the RDA, these factors all coalesced to be the significant variables explaining the variance of the carbon source utilizations by soil microbial communities of natural secondary forest, Masson pine plantation, and slash pine plantation.

The CLPPs of the soils under three types of restored forests might be differentiated along the first axis (see Fig. 4). Twelve of the 15 data points representing the natural secondary forest were on the positive side of the first axis and had higher average score along the first axis than that of Masson pine plantation which in turn was higher than that of slash pine plantation. As distance between data points on the RDA bi-plot denoted the extent of similarity (Lepš and Šmilauer 2003), there were greater similarities between CLPPs of the natural secondary forest and Masson pine (a native species) plantation than those between the natural secondary forest and slash pine (an introduced species) plantation. The arrows denoted the
Fig. 4 Redundancy analysis of soil microbial metabolic structure and factors. Descriptors are as follows: $A N$ available $\mathrm{N}$ content, $S M$ soil moisture content, $S O M$ soil organic matter content, $M B C$ microbial biomass $\mathrm{C}$ content, $\mathrm{TH}$ tree layer Shannon-Wiener index, $p H$ soil $\mathrm{pH}$, Clay clay content

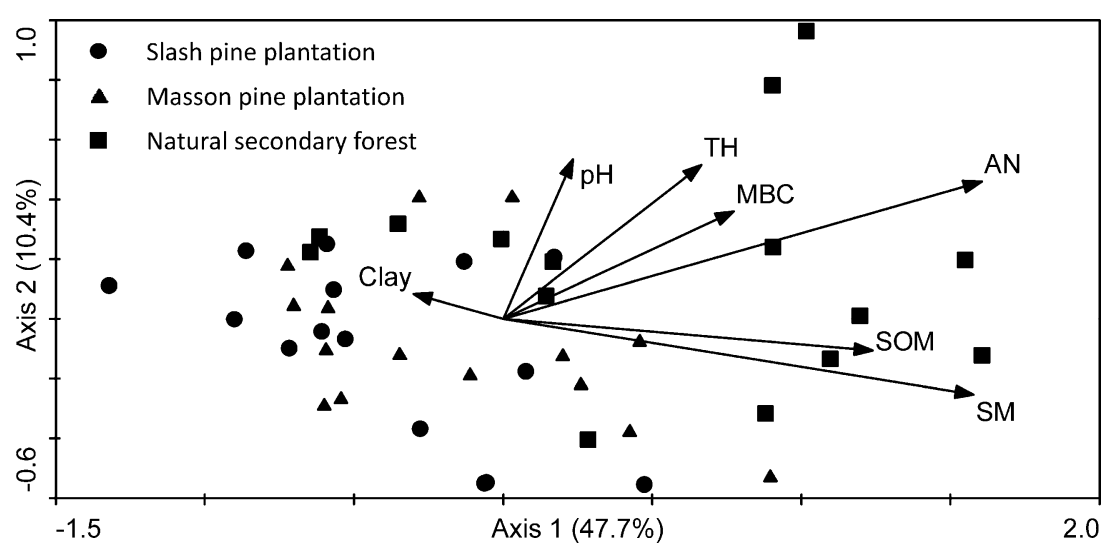


direction by which the designated environmental parameters increase (Lepš and Šmilauer 2003). For natural secondary forest, the data points were located along the pathways the value of environmental factors were increasing, especially the available $\mathrm{N}$ content, soil moisture content, soil organic matter content, microbial biomass $\mathrm{C}$ content, Shannon-Wiener diversity index, and $\mathrm{pH}$. Under equal conditions, the soils of natural secondary forest were higher in nutrient contents, retained more water, and had a richer and larger microbial biomass $\mathrm{C}$. The soil microbial community of slash pine plantation was negatively influenced by the above environmental factors. The high clay contents at the slash pine plantation further aggravated the already stressful environmental conditions. The data points representing Masson pine plantation according to Fig. 4 lay between the natural secondary forest and slash pine plantation in terms of the environmental conditions.

\section{Discussion}

After about 20 years in development, the soil microbial communities in forests restored by three different methods were all well structured and stable, each reflecting the environmental attributes constituted by the forest management method. The functional rather than the taxonomic diversity would govern stability and sustainability of the forest soil microbial ecosystems. CLPPs characterized by the outcomes of Biolog ${ }^{\mathrm{TM}}$ Ecoplate would be an appropriate indicator on the functional diversity of soil microorganisms in metabolizing carbon substrates (Chen et al. 2010; Campbell et al. 1997). Although the outcomes reflected only the patterns of carbon source utilization after the incubation and only selective microbial metabolisms were included (Preston-Mafham et al. 2002; Zheng et al. 2008), CLPPs provided a fast and sensitive way to compare the nature of soil microbial communities under equal basis.

\subsection{Effects of forest restoration types on soil microbial carbon source utilization}

The AWCD development over incubation time reflected the ability of soil microbial communities in utilizing the preselected carbon sources (Zheng et al. 2005). The timedependent development of AWCD responses fitted the logarithmic microbial growth model described by Eq. 2 with the coefficients of fitness, $r^{2}$ equaled 0.96 or greater. Hypothetically, if two soil microbial communities having the same metabolism rate that was characterized by the logarithmic growth rate, $R$, and time for metabolisms to reach one half maximum AWCD, $S$, they should reach the same maximum AWCD and at approximately the same time. If the maximum AWCD of natural secondary forest were higher than the Masson pine and slash pine plantations, implying that the soil microbial communities in Masson and slash pine plantations utilized some of the carbon substrates either through different biochemical pathways or not utilized them at all. This indicated that these two communities did not have the same microbial structure, diversity, and dynamics to metabolize certain carbon substrates as those in the natural secondary forest. Besides, both carbon source utilization richness and diversity index showed that soil microbial community of natural secondary forest had significantly more diverse carbon source utilization than Masson pine plantation, which was in turn higher than slash pine plantation.

Previously, Zheng et al. (2005) reported that carbon source utilization ability and diversity of soil microbial community in the natural secondary forest was significantly larger than that of the slash pine plantation. It was also noted that enzyme activities of the soil in the Masson pine plantation were higher than those in the slash pine plantation (Xue et al. 2005). The soil microbial characteristics would change with the extent the forests had been restored (Harris 2003), the result of our experiment examined the ability of soil microbial communities to utilize carbon sources individually and delineated that the natural secondary forest and coniferous plantations are able to perform the same ecological functions in terms of carbon sources utilization. But the natural secondary forest was more efficient in metabolizing the carbon substrates, its diverse and stable soil microbial ecosystem would be more adaptable to and response more rapidly to environmental changes.

\subsection{Factors influencing soil microbial functional structure}

RDA was used to analyze the causative factors of soil microbial functional community. While the variables selected for analyses mattered (Kaufmann et al. 2004; Lepš and Šmilauer 2003; Liu et al. 2010), the soil-related factors appeared to be the primary driving force for the CLPPs, regardless if they were of the restored forests ( $\mathrm{Li}$ et al. 2008), grass soil (Liu et al. 2010), or contaminated soil (Kaufmann et al. 2004). Logically, they would govern the metabolisms of carbon sources in soils.

RDA showed that seven factors explained $62.9 \%$ carbon source utilization structure, which extended our knowledge of soil carbon source utilization structure (Kaufmann et al. 2004; Liu et al. 2010). These seven factors were soil available $\mathrm{N}$ content, soil microbial biomass $\mathrm{C}$ content, soil moisture content, soil clay content, $\mathrm{pH}$, Shannon-Wiener diversity index of the tree layer, and soil organic matter content. All seven environmental factors except soil $\mathrm{pH}$ and clay content were significantly more favorable in natural secondary forest than those of Masson pine plantation and 
slash pine plantation (see Table 2). This in part explained the high metabolic activity in natural secondary forest. Among these seven factors, available $\mathrm{N}$, soil organic matter, and Shannon-Wiener diversity index of tree layer could be seen as factors directly related to plant nutrients. The $\mathrm{C} / \mathrm{N}$ of the experimental locations varied from $12.8 \pm 0.4$ to $14.3 \pm 0.2$ that were considered marginal in supporting an active and dynamic soil microbial community (Huang 1999). It would be reasonable that available $\mathrm{N}$ content of the soil explained so much of variance. Shannon-Wiener diversity index of the tree layer influenced the metabolic structure by supplying different kinds of litters and root exudates, which could have significant effects on soil microorganisms (Baudoin et al. 2003; Wardle et al. 2004b; Zheng et al. 2005). Soil organic matter is the main carbon source of soil microorganisms.

All these nutrient-related four factors were correlated with litter input. $\mathrm{C} / \mathrm{N}$, lignin $/ \mathrm{N}$ in litters from slash pine were significantly higher than those of Masson pine, which was significantly higher than those from natural secondary forest with many broad-leaf species like Quercus fabri, Cyclobalanopsis glauca, and Cinnamomum camphora (Chen et al. 2011b). This made litters from slash pine plantation the hardest to decompose and thus the least nutrient source for soil microorganisms, followed by Masson pine plantation and natural secondary forest (Chen et al. 2011a). Besides, natural secondary forest had been reported to have higher litter fall than slash pine plantation (Zheng et al. 2005). These two factors lead to the highest nutrients input from litter for natural secondary forest, followed by Masson pine plantation and slash pine plantation.

However, soil moisture content (Marschner and Kalbitz 2003), clay content ( $\mathrm{Liu}$ and $\mathrm{Hu}$ 2004; Young and Crawford 2004), and soil pH (Saleh-Lakha et al. 2005) influenced the carbon source utilization structure by indirectly influencing the availability of nutrients to soil microorganisms. Natural secondary forest had significantly higher soil microbial biomass carbon (see Table 1), which may account for the high potential microbial activity (Kuzyakov 2010). The microbial community structure, climate factors, seasonal variations (Ge et al. 2008), and unintended sampling errors (Zheng et al. 2005) were not included in the analysis and were all possible causative factors.

\subsection{Implications for forest restoration}

In this study, we investigated the microbial communities of three common types of restored forests in terms of their ability to metabolize 31 preselected carbon substrates. The first was a passive restoration approach of re-establishing the natural secondary forest by not disturbing the harvested forest (Zhang and Dong 2010) and allowing the vegetation to re-establish in natural and near natural manner (Fu et al. 2004; Sayer et al. 2004; Stone 2009; Wei et al. 2009; Zheng et al. 2008). The second type of restoration was to reforest with an introduced species dependent on levels of forest and soil degradation, residual vegetation, and desirable restoration outcomes (Chazdon 2008). The third type of restoration involved the artificial means of establishing a plantation of native species (Rey-Benayas et al. 2010). Transformation of natural forest to economic forest or farmland would lead to decline in soil fertility (Liu et al. 2009) and high restoration costs (Stone 2009). Chazdon (2008) noted that natural restoration was the least costly and most rapid, followed by restoration with native species, and the commercially based restoration with the aim of harvesting forest products was the most costly. Apart from cost, forest restoration must consider well being of the ecosystems and balance the ecological and economic benefits (Stone 2009).

The outcomes of our investigation revealed that the soil microbial communities in these three types of restored forests would perform essentially the same ecological functions in terms of their ability of metabolizing the preselected carbon sources. However, the soil microbial communities of these three restored forests showed significantly different carbon source utilization structure and would sometimes engage different biochemical pathways in metabolizing the carbon substrates. In all, the microbial community of natural secondary forest was more efficient in utilizing the carbon substrates than those of the artificially restored plantations because its soils possessed greater amount of available nutrients, stored more water, contained greater amount and more diverse organic matter, and had a more diverse microbial community. As a result, the natural secondary forest was expected to be more responsive to environmental changes (Huang 1999) and would be more stable in coping with external stresses. Among the two artificially restored forests, plantation of native species was preferred over that of introduced species in terms of threats of ecological crises (Parrotta et al. 1997; Wei et al. 2009; Zhang and Chu 2010). There were larger differences in CLPPs between the natural secondary forest and the slash pine plantation than between the natural secondary forest and the Masson pine plantation. Caution should be noted on the possible ecological consequences when restorations employed cultivation of introduced species for commercial harvest of timbers.

Multiple regression analyses showed that the carbon source utilization intensity was positively correlated with the available $\mathrm{N}$ of soils that carbon source utilization intensity $=0.626 \times$ standardized available $\mathrm{N}$ content $\left(r^{2}=\right.$ $0.374, p<0.001)$. This further indicated that nitrogen fertilizer application (Burton et al. 2010) was a possible 
way to improve the management of Masson pine plantation and slash pine plantation in Southern China.

\section{Conclusions}

We studied the ecological structure, function, and diversity of soil microbial communities of well-established naturally regenerated secondary forest, restored native Masson pine plantation, and restored introduced slash pine plantation in the red soil region of Southern China by delineating the carbon source metabolisms of the communities using Biolog ${ }^{\mathrm{TM}}$ Ecoplates incubation. Based on the standard measurement parameters of maximum AWCD, time to reach one half maximum $\mathrm{AWCD}$, logarithmic metabolic rate, and richness of carbon metabolism, the soil microbial community of natural secondary forest exhibited more diverse carbon source utilization pattern and was capable of metabolizing more carbon substrates in a more efficient manner than those of the restored coniferous plantations. In turn, the carbon source utilization pattern of soil microbial communities of Masson pine plantation was more diverse and capable of utilizing carbon substrates more efficiently than those of the slash pine plantation.

When the carbon source utilization was further analyzed by examining the logarithmic growth curve of individual carbon substrates, it showed that soil microbial communities of all three types of forests were able to metabolize the 31 preselected carbon substrates. For the metabolism of some substrates, the lag time was considerably longer and/ or the logarithmic metabolic rate was considerably slower in the soil microbial communities of Masson pine and slash pine plantations. It indicated that these communities had the ability to acclimate and/or adopt different biochemical pathways to metabolize the carbon substrates.

The characteristics of soil microbial communities were inherent of the forest management and cultivation practices that eventually determine the environment in which the soil microbes inhabit. Among them, the soil-related environmental factors including contents of available $\mathrm{N}$, moisture, organic matter, microbial biomass $\mathrm{C}$, clay, and $\mathrm{pH}$ were most significant factors in determining the attributes resulting microbial community.

Acknowledgments This research was funded by National Nature Science of China (40871130), National Key Basic Research Program of China (Grant 2009CB421105), and Special Foundation from State Key Laboratory of Urban and Regional Ecology. We thank Shengbin Chen, Zhigang Huang, Yan Liu, Hongxing Chen, Dali Jiang, Shunliang Wang, and Xiangming Zeng for giving help in soil sampling and plant survey. We thank Xiu Yuan, Laiye Qu, Meie Wang, Weiping Chen, and Zhiguo Fang for giving advices on the manuscript. We also thank the anonymous reviewers for their invaluable suggestions.

\section{References}

Bao SD (2000) Soil and agricultural chemical analysis, 3rd edn. China Agricultural Press, Beijing

Baudoin E, Benizri E, Guckert A (2003) Impact of artificial root exudates on the bacterial community structure in bulk soil and maize rhizosphere. Soil Biol Biochem 35(9):1183-1192

Benayas JMR, Newton AC, Diaz A, Bullock JM (2009) Enhancement of biodiversity and ecosystem services by ecological restoration: a meta-analysis. Science 325(5944):1121-1124

Burton J, Chen CR, Xu ZH, Ghadiri H (2010) Soil microbial biomass, activity and community composition in adjacent native and plantation forests of subtropical Australia. J Soils Sediments 10 (7):1267-1277

Campbell CD, Grayston SJ, Hirst DJ (1997) Use of rhizosphere carbon sources in sole carbon source tests to discriminate soil microbial communities. J Microbiol Meth 30(1):33-41

Chazdon RL (2008) Beyond deforestation: restoring forests and ecosystem services on degraded lands. Science 320 (5882):1458-1460

Chen FL, Jiang B, Zhang K, Zheng H, Xiao Y, Ouyang ZY, Tu NM (2011a) Relationships between initial chemical composition of forest leaf litters and their decomposition rates in degraded red soil hilly region of South China. Chin J Appl Ecol 22(3):575-580 (in Chinese)

Chen FL, Zheng H, Ouyang ZY, Zhang K, Tu NM (2011b) Responses of microbial community structure to the leaf litter composition. Acta Pedol Sin 48(2):185-193 (in Chinese)

Chen Z, Wang XK, Yao FF, Zheng FX, Feng ZZ (2010) Elevated ozone changed soil microbial community in a rice paddy. Soil Sci Soc Am J 74(3):829-837

Costanza R (1997) The value of the world's ecosystem services and natural capital. Nature 387:253-260

Fierer N, Jackson RB (2006) The diversity and biogeography of soil bacterial communities. Proc Natl Acad Sci U S A 103(3):626631

$\mathrm{Fu}$ BJ (2010) Trends and priority areas in ecosystem research of China. Geogr Res 29(3):383-396 (in Chinese)

Fu BJ, Liu SL, Chen LD, Lv YH, Qiu J (2004) Soil quality regime in relation to land cover and slope position across a highly modified slope landscape. Ecol Res 19(1):111-118 (In Chinese)

Fuhrman JA (2009) Microbial community structure and its functional implications. Nature 459(7244):193-199

Garland JL, Mills AL (1991) Classification and characterization of heterotrophic microbial communities on the basis of patterns of community-level sole-carbon-source utilization. Appl Environ Microbiol 57(8):2351-2359

Ge Y, He JZ, Zhu YG, Zhang JB, Xu ZH, Zhang LM, Zheng YM (2008) Differences in soil bacterial diversity: driven by contemporary disturbances or historical contingencies? ISME J 2 (3):254-264

Hackett CA, Griffiths BS (1997) Statistical analysis of the time-course of Biolog substrate utilization. J Microbiol Meth 30(1):63-69

Harris JA (2003) Measurements of the soil microbial community for estimating the success of restoration. Eur J Soil Sci 54(4):801808

Harris J (2009) Soil microbial communities and restoration ecology: facilitators or followers? Science 325(5940):573-574

Huang CY (1999) Soil science, 1st edn. China Agricultural Press, Beijing

Kaufmann K, Christophersen M, Buttler A, Harms H, Höhener P (2004) Microbial community response to petroleum hydrocarbon contamination in the unsaturated zone at the experimental field site Vaerløse, Denmark. FEMS Microbiol Ecol 48 (3):387-399 
Kohler F, Hamelin J, Gillet F, Gobat JM, Buttler A (2005) Soil microbial community changes in wooded mountain pastures due to simulated effects of cattle grazing. Plant Soil 278(1):327-340

Kuzyakov Y (2010) Priming effects: interactions between living and dead organic matter. Soil Biol Biochem 42:1363-1371

Lepš J, Šmilauer P (2003) Multivariate analysis of ecological data using CANOCO. Cambridge University Press, New York

Li SP, Cai ZC, Yang H (2008) Effect of red soil properties under different vegetation types on bacterial carbon source utilization. Appl Environ Biol 14(6):793-797

Lindstorm E, Barry R, Braddock JF (1998) Microbial community analysis: a kinetic approach to constructing potential $\mathrm{C}$ source utilization patterns. Soil Biol Biochem 30(2):231-239

Liu GH, Fu BJ, Chen LD, Guo XD (2000) Characteristics and distributions of degraded ecological types in China. Acta Ecol Sin 20(1):13-19 (in Chinese)

Liu JG, Li SX, Ouyang ZY, Tam C, Chen XD (2008) Ecological and socioeconomic effects of China's policies for ecosystem services. Proc Natl Acad Sci U S A 105(28):9477-9482

Liu X, Zhang GC, Heathman GC, Wang YQ, Huang CH (2009) Fractal features of soil particle-size distribution as affected by plant communities in the forested region of Mountain Yimeng, China. Geoderma 154(1-2):123-130

Liu Y, Hu H (2004) Effects of landscape and soil utilization styles on red soil physical properties. J Soil Water Conserv 18(1):22-26 (in Chinese)

Liu ZF, Fu BJ, Zheng XX, Liu GH (2010) Plant biomass, soil water content and soil N:P ratio regulating soil microbial functional diversity in a temperate steppe: A regional scale study. Soil Biol Biochem 42(3):445-450

Manzoni S, Jackson RB, Trofymow JA, Porporato A (2008) The global stoichiometry of litter nitrogen mineralization. Science 321(5889):684-686

Marschner B, Kalbitz K (2003) Controls of bioavailability and biodegradability of dissolved organic matter in soils. Geoderma 113(3-4):211-235

Meyer CK, Baer SG, Whiles MR (2008) Ecosystem recovery across a chronosequence of restored wetlands in the Platte River valley. Ecosystems 11(2):193-208

Mondini C, Insam H (2003) Community level physiological profiling as a tool to evaluate compost maturity: a kinetic approach. Eur J Soil Biol 39(3):141-148

Ouyang ZY, Wang XK, Miao H (1999) A primary study on Chinese terrestrial ecosystem services and their ecological-economic values. Acta Ecol Sin 19(5):607-613 (in Chinese)

Parrotta JA, Turnbull J, Jones N (1997) Catalyzing native forest regeneration on degraded tropical lands. For Ecol Manag 99(1-2):1-7

Preston-Mafham J, Boddy L, Randerson PF (2002) Analysis of microbial community functional diversity using sole-carbon-source utilisation profiles - a critique. FEMS Microbiol Ecol 42(1):1-14

Ren H, Li ZA, Shen WJ, Yu ZY, Peng SL, Liao CH, Ding MM, Wu JG (2006) Changes of diversity and ecosystem services in forest restoration process in South China. Sci China C Life Sci 36 (006):563-569 (in Chinese)

Ren H, Shen WJ, Lu HF, Wen XY, Jian SG (2007) Degraded ecosystems in China: status, causes, and restoration efforts. Landscape Ecol Eng 3(1):1-13

Rey-Benayas JM, Galván I, Carrascal LM (2010) Differential effects of vegetation restoration in Mediterranean abandoned cropland by secondary succession and pine plantations on bird assemblages. For Ecol Manag 260(1):87-95

Roberts L, Stone R, Sugden A (2009) The rise of restoration ecology. Science 325(5940):555

Saetre P, Bååth E (2008) Spatial variation and patterns of soil microbial community structure in a mixed spruce-birch stand. Soil Biol Biochem 32(7):909-917
Saleh-Lakha S, Miller M, Campbell RG, Schneider K, Elahimanesh P, Hart MM, Trevors JT (2005) Microbial gene expression in soil: methods, applications and challenges. J Microbiol Meth 63(1):1-19

Sayer J, Chokkalingam U, Poulsen J (2004) The restoration of forest biodiversity and ecological values. For Ecol and Manag 201(1):3-11

Shannon CE (1948) Discrete noiseless systems. In: TboTotUo I (ed) A mathematical theory of communication. University of Illinois Press, Chicago, pp 3-19

Simmons MT, Venhaus HC, Windhager S (2007) Exploiting the attributes of regional ecosystems for landscape design: the role of ecological restoration in ecological engineering. Ecol Eng 30 (3):201-205

Stone R (2009) Nursing China's ailing forests back to health. Science 325(5940):556

Tian DL, Xiang WH, Yan WD (2004) Comparison of biomass dynamic and nutrient cycling between Pinus massomiana plantation and Pinus elliottii plantation. Acta Ecol Sin 24 (10):2207-2210 (in Chinese)

Vance ED, Brookes PC, Jenkinson DS (1987) An extraction method for measuring soil microbial biomass C. Soil Biol Biochem 19 (6):703-707

Wang D, Fu BJ, Zhao WW, Hu HF, Wang YF (2008) Multifractal characteristics of soil particle size distribution under different land-use types on the Loess Plateau, China. Catena 72(1):29-36

Wardle DA, Bardgett RD, Klironomos JN, Setala H, Van Der Putten WH, Wall DH (2004a) Ecological linkages between aboveground and belowground biota. Science 304(5677):1629-1633

Wardle DA, Walker LR, Bardgett RD (2004b) Ecosystem properties and forest decline in contrasting long-term chronosequences. Science 305(5683):509-513

Wei Y, Ouyang ZY, Miao H, Zheng H (2009) Exotic Pinus carbaea causes soil quality to deteriorate on former abandoned land compared to an indigenous Podocarpus plantation in the tropical forest area of southern China. J Forest Res-JPN 14 (4):221-228

Whitham TG, DiFazio SP, Schweitzer JA, Shuster SM, Allan GJ, Bailey JK, Woolbright SA (2008) Extending genomics to natural communities and ecosystems. Science 320(5875):492-495

Winding A (1994) Fingerprinting bacterial soil communities using Biolog microtitre plates. In: Ritz K, Dighton J, Giller KE (eds) Beyond the biomass. Wiley, New York, pp 85-94

Xue L, Wu M, Xu Y, Li Y, Qu M (2005) Soil nutrients and microorganisms in soils of typical plantations in South China. Acta Pedol Sin 42(6):1017-1023 (in Chinese)

Young IM, Crawford JW (2004) Interactions and self-organization in the soil-microbe complex. Science 304(5677):1634-1637

Zhang H, Chu L (2010) Plant community structure, soil properties and microbial characteristics in revegetated quarries. Ecological Engineering. doi:10.1016/i.ecoleng.2010.05.010

Zhang JT, Dong Y (2010) Factors affecting species diversity of plant communities and the restoration process in the loess area of China. Ecol Eng 36(3):345-350

Zhang M, Cha X (2009) Progress in models of comprehensive control of eroded and degraded land in red soil region. Subtropical Soil Water Conserv 21(4):34-39 (in Chinese)

Zhao T, Ouyang ZY, Zheng H, Wang XK, Miao H (2004) Forest ecosystem services and their valuation in China. J Nat Resour 19 (004):480-491 (in Chinese)

Zheng H, Chen FL, Ouyang ZY, Tu NM, Xu WH, Wang XK, Miao H, Li XQ, Tian YX (2008) Impacts of reforestation approaches on runoff control in the hilly red soil region of Southern China. J Hydrol 356(1-2):174-184

Zheng H, Ouyang ZY, Wang XK, Fang ZG, Zhao TQ, Miao H (2005) Effects of regenerating forest cover on soil microbial communities: a case study in hilly red soil region, Southern China. For Ecol Manag 217(2-3):244-254 